\title{
GABAergic Antagonists Block the Inhibitory Effects of Serotonin in the Lateral Amygdala: A Mechanism for Modulation of Sensory Inputs Related to Fear Conditioning
}

\author{
Grace E. Stutzmann and Joseph E. LeDoux \\ Center for Neural Science, New York University, New York, New York 10003
}

Neurons in the lateral amygdala (LA) receive glutamatergic sensory input from the auditory thalamus and auditory cortex, and these inputs can be modulated by serotonin $(5-\mathrm{HT})$. In the present study, we examined whether serotonergic inhibition of glutamatatergic excitation in the LA occurs via activation of GABAergic interneurons. Single-unit extracellular activity in the LA was recorded in response to iontophoretically applied glutamate. Concurrent application of 5-HT reduced the number of glutamate-evoked action potentials in the majority of neurons tested. GABA antagonists were then iontophoresed with both

Fear conditioning is widely used as a model system for understanding how the brain forms and stores information about aversive emotional experiences. Research on the neural basis of fear conditioning points to the amygdala as a key interface between harmful stimuli in the environment and motor systems that produce defense responses (Davis et al., 1994; Fanselow, 1994; LeDoux, 1994). Sensory information about stimuli that are harmful enter the amygdala by way of the lateral nucleus (LA) (LeDoux et al., 1990). The LA, in turn, projects to other amygdala areas (Pitkanen et al., 1997), which control defense responses (see Davis, 1992).

The LA receives dense serotonergic inputs from the dorsal raphe (Sadikot and Parent, 1990); several serotonin (5-HT) receptor subtypes are present in the LA (Radja et al., 1991); and 5-HT levels increase in the LA during amygdala-dependent processes such as fear conditioning (Inoue et al., 1993; Kawahara et al., 1993). Given that serotonin is known to be a widespread modulator of neuronal activity, we recently examined the contribution of serotonin to the modulation of sensory processing within the LA (Stutzmann et al., 1998). Iontophoresis of 5-HT inhibited the excitation elicited by concurrent iontophoresis of glutamate or by electrical stimulation of glutamatergic inputs from the auditory thalamus or auditory cortex. 5-HT-induced inhibition of synaptic activity could be attributable to a direct inhibitory effect of 5-HT on excitatory neurons postsynaptic to the sensory afferents or could be attributable to activation of GABAergic cells through excitatory 5-HT receptors in the LA, which then inhibit excitatory cells. In support of the latter possibility is the observation that $5-\mathrm{HT}_{3}$ and possibly $5-\mathrm{HT}_{2}$ receptor

Received Dec. 18, 1998; revised March 10, 1999; accepted March 12, 1999.

This work was supported by National Institute of Mental Health Grants RO1MH46516 and 1K02-M H00956 and the W. M. Keck Foundation.

Correspondence should be addressed to Joseph E. LeDoux, Center for Neural Science, New York University, 4 Washington Place, Room 808, New York, NY 10003 .

Copyright (C) 1999 Society for Neuroscience $\quad 0270-6474 / 99 / 190001-04 \$ 05.00 / 0$ glutamate and 5-HT. Of the neurons that were inhibited by $5-\mathrm{HT}$, concurrent application of the GABA antagonists significantly reversed this effect. Application of the GABA antagonists alone had little or no effect on basal neuronal activity. We conclude that the 5-HT-induced inhibition of glutamatergic activity occurs in part through activation of serotonergic receptors on GABAergic interneurons.

Key words: electrophysiology; iontophoresis; rat; glutamate; anxiety; sensory modulation

subtypes are present on GABA-containing cells in the LA (Sheldon and Aghajanian, 1990; Radja et al., 1991; Morales and Bloom, 1997). In this study, we used microiontophoresis to locally apply drugs very close to the recording site to examine the role of GABA interneurons in serotonin-induced inhibition of glutamate activity. If 5-HT inhibits glutamatergic excitation by way of GABA interneurons, blockade of GABA receptors should eliminate the inhibition by 5 -HT.

\section{MATERIALS AND METHODS}

Experiments were conducted on male Sprague Dawley rats weighing 250-375 gm. Animals were housed on an alternating $12 \mathrm{hr}$ light/dark cycle (lights on at 7 A.M., lights off at 7 P.M.). Procedures were performed in accordance with National Institutes of Health guidelines.

Rats were anesthetized with urethane $(1.6 \mathrm{mg} / \mathrm{kg})$ and placed in a stereotaxic frame. The cranium above the LA, medial nucleus of the medial geniculate/posterior-intralaminar nucleus ( $\mathrm{MGm} / \mathrm{PIN}$ ), and secondary auditory cortex (TE3) regions were exposed, and the dura was retracted. Electrodes were then placed into the LA using a hydraulic microdrive, and bipolar stimulating electrodes were manually lowered into the $\mathrm{MGm} / \mathrm{PIN}$ region [inserted at a $10^{\circ}$ angle in the anteroposterior (AP) plane] and the TE3 region (inserted in a $20^{\circ}$ angle in the AP plane).

As an additional physiological measure to confirm the location of the recording electrode, sensory afferents known to project to the LA were stimulated (Romanski and LeDoux, 1993), and evoked action potentials were recorded. The TE3 and MGm/PIN regions were stimulated with

This article is published in The Journal of Neuroscience, Rapid Communications Section, which publishes brief, peerreviewed papers online, not in print. Rapid Communications are posted online approximately one month earlier than they would appear if printed. They are listed in the Table of Contents of the next open issue of JNeurosci. Cite this article as: JNeurosci, 1999, 19:RC8 (1-4). The publication date is the date of posting online at www.jneurosci.org.

http://www.jneurosci.org/cgi/content/full/3062 
single pulses $(100-800 \mu \mathrm{A}, 0.3 \mathrm{~Hz}, 300 \mu \mathrm{sec}$ duration) from a Grass Instruments (Quincy, MA) 88 constant current stimulator delivered through a bipolar stimulating electrode $(r=30-40 \mathrm{~K} \Omega)$. Electrode stereotaxic coordinates from the interaural line (in millimeters) were as follows: recording electrode, AP, 5.8-6.2; mediolateral (ML), 5.2; and dorsoventral (DV), 6.0-7.0; MGm/PIN stimulating electrode, AP, 3.8; ML, 3.0; and DV, 6.1; and TE3 stimulating electrode, AP, 4.0; ML, 6.8; and DV 3.3 (Paxinos and Watson, 1986).

Single-unit recordings were obtained from glass micropipettes $(1-3 \mu \mathrm{m}$ tip diameter, 10-20 M $\Omega$ impedance) filled with $2.5 \%$ Pontamine sky blue in $0.5 \mathrm{M}$ sodium acetate. Single-unit activity was amplified, filtered, and discriminated. Undiscriminated output was viewed on a Tektronix (Wilsonville, OR) storage oscilloscope, and discriminated output was digitized for the construction of poststimulus histograms using a Cambridge Electronic Design (Cambridge, UK) 1401 computer interface.

The technique of microiontophoresis was used as a way to effectively deliver various compounds within the immediate area of the recording site. With this technique, only very small quantities of drug are released from the electrode tip via current ejection. This decreases the possibility that compounds will diffuse far from the neuron recorded from or into neighboring nuclei (as is seen with local infusion methods) but does not allow for accurate dose-response analysis. Microiontophoresis was accomplished by gluing a five-barrel micropipette (10-20 $\mu \mathrm{m}$ tip diameter) adjacent to the single-barrel recording electrode with a light curing dental fixative (Silux, 3M, St. Paul, MN). The tip of the recording pipette extended 15-35 $\mu \mathrm{m}$ beyond the tip of the iontophoretic pipette. The center barrel was filled with $0.9 \%$ saline for automatic current balancing. The remaining barrels were filled with glutamate (L-glutamic acid, 10 $\mathrm{mM}, \mathrm{pH} 8.0,-5.0$ to $-30 \mathrm{nA}$ ejection current, $10 \mathrm{nA}$ holding current), serotonin (serotonin creatinine sulfate, $20 \mathrm{~mm}$, pH 4.0, 10-80 nA ejection current, $-10 \mathrm{nA}$ holding current), bicuculline methiodide $(5 \mathrm{mM}, \mathrm{pH}$ $3.5,20-80 \mathrm{nA}$ ejection current), and 2-OH-saclofen $(20 \mathrm{~mm}, \mathrm{pH} 3.5$, 20-80 nA ejection current). Bicuculline methiodide and 2-OH-saclofen were placed in the same electrode barrel. Drugs were purchased from Research Biochemicals (Natick, MA).

Placements of recording sites were marked by iontophoretically depositing Pontamine sky blue or locating the electrode tracks in the LA. Animals were perfused with $10 \%$ formalin and post-fixed, and brains were cut on a sliding microtome into $50-\mu \mathrm{m}$-thick sections. Sections were Nissl-stained and coverslipped, and the location of the dye spot or electrode tracks was determined under light microscopic examination.

\section{RESULTS}

Neurons in the LA were either silent or had low firing rates $(<1$ $\mathrm{Hz}$ ), as is typical for this region (Clugnet et al., 1990). LA neurons were therefore identified via synaptic stimulation from the $\mathrm{MGm} / \mathrm{PIN}$ and TE3. Iontophoretic application of glutamate was then used to evoke action potentials in these LA neurons that were postsynaptic to the MGm/PIN and/or TE3. A representative distribution of the recording sites and relevant amygdala nuclei are shown in a Gisma-stained coronal section in Figure 1.

The effects of iontophoretically applied 5-HT were tested on neurons activated via glutamate application. After accumulating spikes during this control period, 5-HT was concurrently applied during these conditions, and the total number of spikes was again analyzed and compared with the control period. GABA antagonists were then iontophoresed in conjunction with glutamate and 5-HT, and the number of spikes evoked was analyzed during this phase and compared with the original firing rates during glutamate alone and the presence of 5-HT and glutamate together.

Of the 37 neurons activated by glutamate, 32 were inhibited by the concurrent application of 5-HT. The criterion for inhibition was set at $33 \%$ reduction in the number of spikes relative to before 5-HT application. In the majority of these neurons, the inhibitory effects of 5-HT were attenuated by the coadministration of GABAergic antagonists, whereas six neurons had no response. Representative histograms demonstrating typical responses of single neurons are shown in Figure 2. Figure 3 shows the group data for the average number of spikes evoked during

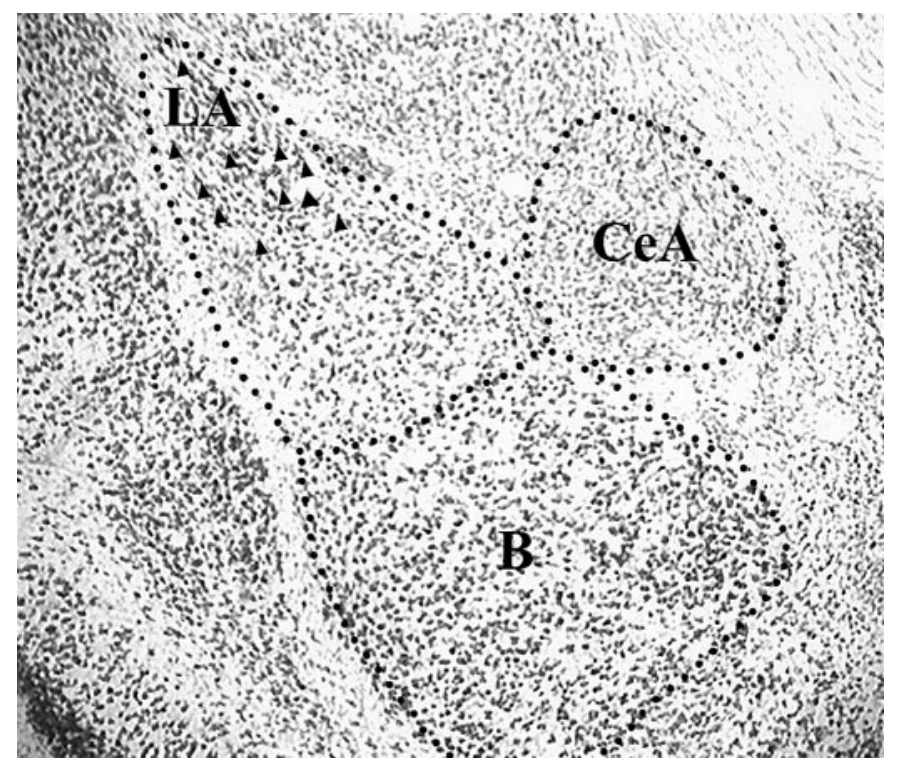

Figure 1. Gisma-stained coronal section of the rat brain, showing the region containing the lateral amygdala and representative electrode recording sites. Also outlined are the basal $(B)$ and central nuclei of the amygdala $(\mathrm{CeA})$.

each drug condition over a 1 min period. A one-way ANOVA demonstrates a significant difference in the number of spikes evoked among drug application groups $\left(F_{(2)}=6.14 ; p<0.01\right)$. Newman-Keuls post hoc analysis demonstrated that the 5-HT group differs significantly from the glutamate $(p<0.01)$ and glutamate-5-HT-GABA antagonist group $(p<0.01)$, whereas the glutamate and glutamate-5-HT-GABA antagonist groups are not significantly different.

In several of the neurons that showed a reversal of 5-HT inhibition, glutamate and the GABA antagonists were iontophoresed together to ensure that blockade of the GABA receptors was not enhancing excitatory activity on its own $(n=11)$. A two-tailed paired $t$ test indicates these conditions are not significantly different $\left(t_{(10)}=1.18 ; p>0.05\right)$. In several of these neurons, the GABA antagonists were iontophoresed alone $(n=$ 13) to ensure that spontaneous activity was not affected. Consistent with the results of Li et al. (1996), there was no change from the normally quiescent state of these neurons with blockade of the GABA receptors.

\section{DISCUSSION}

The purpose of this study was to examine interactions among glutamatergic sensory afferents, GABAergic interneurons, and serotonergic inputs to LA cells. The results suggest that glutamatergic inputs to the LA can be modulated by 5-HT through activation of GABAergic interneurons. 5-HT, when locally applied to glutamate-activated neurons, inhibits this excitatory input, and blockade of GABA receptors reverses this effect in many of the neurons tested. This modulation can potentially have significant effects on the overall flow of information conducted through the amygdala and thereby influence the ability of the amygdala to control autonomic, endocrine, and behavioral responses normally elicited by threatening stimuli.

\section{GABA antagonists reverse the inhibitory effects of 5-HT}

The amygdala is highly modulated by GABA. It contains both $\mathrm{GABA}_{\mathrm{A}}$ and $\mathrm{GABA}_{\mathrm{B}}$ receptors (Bowery et al., 1987), GABAer- 

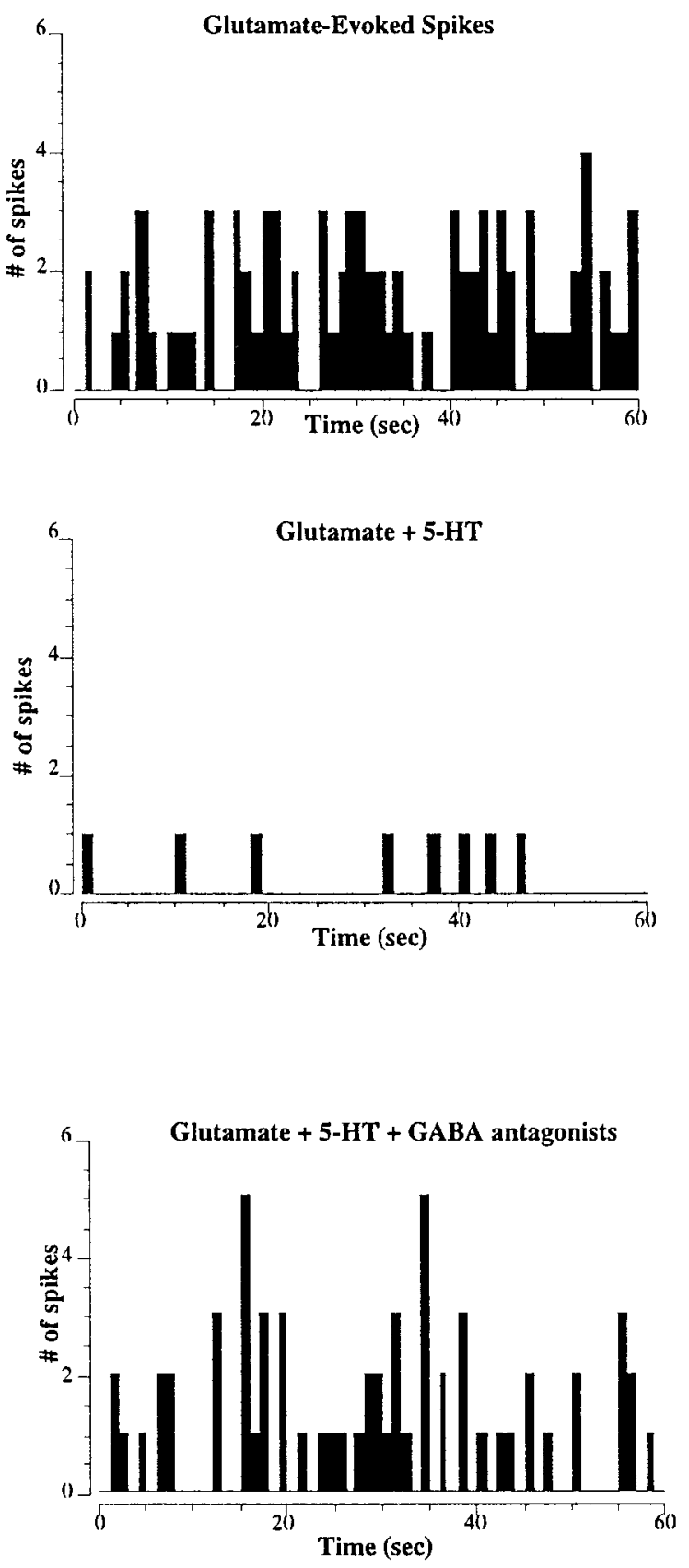

Figure 2. Time histograms of glutamate-evoked spikes over a $1 \mathrm{~min}$ period, inhibition by 5-HT when released with glutamate, and the reversal of this effect with the addition of GABA antagonists.

gic interneurons (McDonald, 1985) and 5-HT receptors anatomically and physiologically involved in GABAergic activation (Gellman and Aghajanian, 1994; Morales and Bloom, 1997). Previous work has demonstrated that glutamate activation of LA neurons can be inhibited by local serotonin release and that this depends on adrenal glucocorticoid hormones (Stutzmann et al., 1998). The present study implicates GABAergic neurons in this inhibition. Iontophoretic application of GABA antagonists attenuated the inhibitory effects of 5-HT, returning glutamate-evoked neuronal activity to within baseline levels in many LA neurons. It should be noted that other regulatory mechanisms are likely used in the LA, because not all neurons inhibited by 5-HT were reversed by GABA blockade.

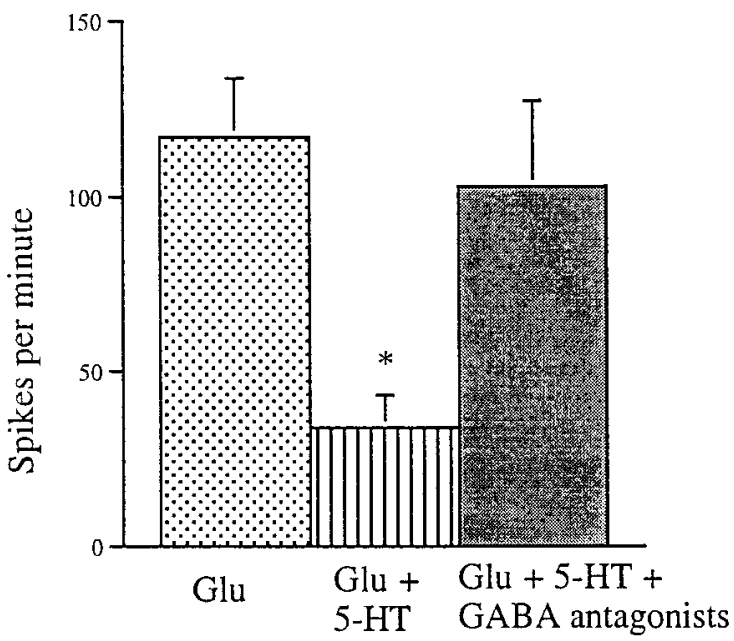

$$
\begin{aligned}
& \text { * significantly different from Glu and } \\
& \text { Glu + 5-HT + GABA antagonists. } \\
& \mathrm{p}<0.05
\end{aligned}
$$

Figure 3. Bar graph demonstrating number of spikes evoked during various iontophoretically applied compounds. Glutamate $(G l u)$ evoked action potentials in normally quiescent lateral amygdala neurons, and coapplication of 5-HT inhibited this effect. The additional application of $\mathrm{GABA}_{\mathrm{A}}$ and $\mathrm{GABA}_{\mathrm{B}}$ antagonists reversed the inhibitory effects of 5-HT.

\section{5-HT/GABAergic modulation in other brain regions}

Several recent studies examined 5-HT modulation of glutamate transmission elsewhere in the brain and have proposed a similar mechanism for the modulation of sensory input to the LA. The hippocampus has been examined in detail. Median raphe serotonergic neurons heavily innervate GABAergic interneurons in the CA1 region of the hippocampus (Moore and Halaris, 1975), and in these GABAergic neurons, serotonin facilitates inhibitory transmission through activation of the $5-\mathrm{HT}_{3}$ receptor subtype, suppressing the firing of CA1 pyramidal cells (Ropert and Guy, 1991). In addition, neurons of the cerebellar nuclei receive a serotonergic input, which suppresses excitatory amino acidinduced activity, as well as potentiating the inhibitory effects of GABA (Kitzman and Bishop, 1997).

\section{Proposed circuitry model}

The results of this study suggest that excitatory serotonin receptors activate GABAergic neurons, which locally regulate LA neurons receiving glutamatergic sensory afferents. A schematic of the proposed connections is presented in Figure 4. Stimuli (including environmental stressors) that increase 5-HT levels in the amygdala would activate 5-HT receptors on GABAergic neurons, facilitating GABAergic release onto LA projection neurons.

\section{Clinical implications}

Dysfunctions in the 5-HT system have been linked to multiple anxiety and stress disorders (Eison and Eison, 1994), and this connection is consistent with malfunctioning of serotonergic modulation in the amygdala (Gargiulo et al., 1996; Liang, 1998). Decreased serotonergic functioning might result in deficient GABAergic modulation of excitatory sensory afferents, perhaps allowing innocuous sensory signals to be processed through the LA as emotionally stimulating events. Overall, the net effect of 5-HT acting through GABAergic mechanisms in the LA appears 


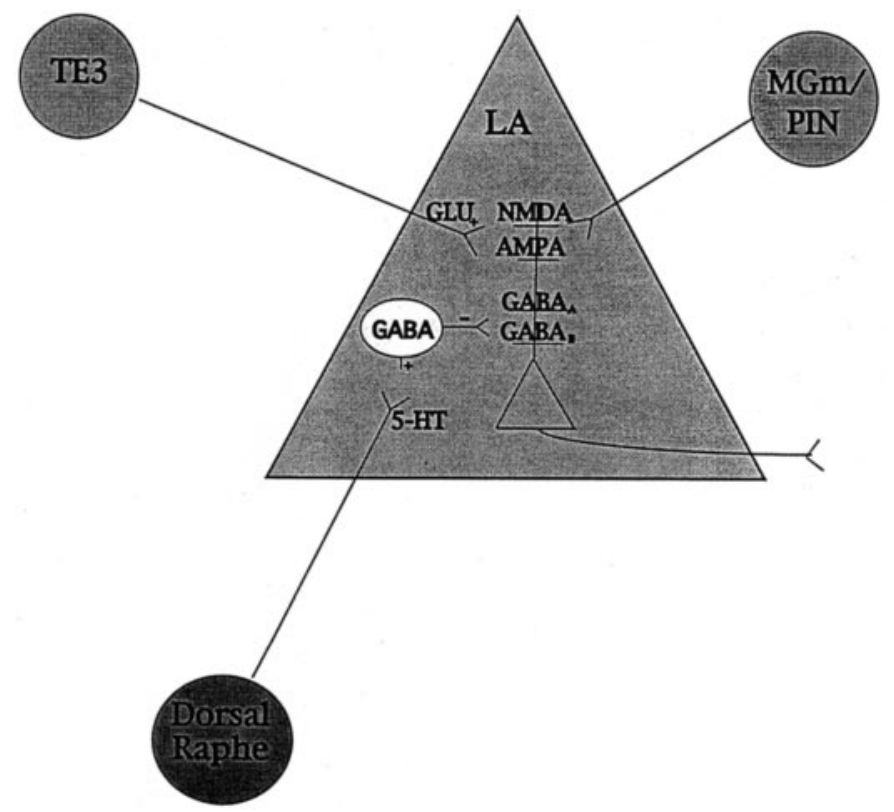

Figure 4. Schematic illustrating possible modulatory mechanisms of sensory input to the LA. Glutamatergic auditory afferents impinge on LA projections neurons containing both glutamate and GABA receptors and GABAergic interneurons. Interneurons containing the $5-\mathrm{HT}_{3}$ or $5-\mathrm{HT}_{2}$ receptor receive a serotonergic input from the dorsal raphe nucleus. Activation of these excitatory receptors increases GABA release onto projection neurons, inhibiting activation from sensory afferents. The net effect is a reduction in sensory transmission to the central nucleus.

to be inhibitory and may therefore serve as a modulator of affective sensory processing.

\section{REFERENCES}

Bowery N, Hudson A, Price G (1987) GABA $_{A}$ and GABA $_{B}$ receptor site distribution in the rat central nervous system. Neuroscience 20:365-383.

Clugnet M, LeDoux J, Morrison S (1990) Unit responses evoked in the amygdala and striatum by electrical stimulation of the medial geniculate body. J Neurosci 10:1055-1061.

Davis M (1992) The role of the amygdala in conditioned fear. In: The amygdala: neurobiological aspects of emotion, memory, and mental dysfunction (Aggleton JP, ed), pp 255-306. New York: Wiley-Liss.

Davis M, Rainnie D, Cassell M (1994) Neurotransmission in the rat amygdala related to fear and anxiety. Trends Neurosci 17:208-214.

Eison A, Eison M (1994) Serotonergic mechanisms in anxiety. Prog Neuropsychopharmacol Biol Psychiatry 18:47-62.

Fanselow MS (1994) Neural organization of the defensive behavior system responsible for fear. Psychonomic Bull Rev 1:429-438.

Gargiulo PA, Viana MB, Graeff FG, Silva MA, Tomaz C (1996) Effects of anxiety and memory of systemic and intra-amygdala injection of 5-HT3 receptor antagonist BRL 46470A. Neuropsychobiology 33:189-195.

Gellman R, Aghajanian G (1994) Serotonin 2 receptor-mediated excitation of interneurons in piriform cortex: antagonsim by atypical antipsychotic drugs. Neuroscience 58:515-525.

Inoue T, Koyama T, Yamashita I (1993) Effect of conditioned fear stress on serotonin metabolism in the rat brain. Pharmacol Biochem Behav 44:371-374.

Kawahara H, Yoshida M, Yokoo H, Nishi M, Tanaka M (1993) Psychological stress increases serotonin release in the amygdala and prefrontal cortex assessed by in vivo microdialysis. Neurosci Lett 162:81-84.

Kitzman P, Bishop G (1997) The physiological effects of serotonin on spontaneous and amino acid-induced activation of cerebellar nuclear cells: an in vivo study in the cat. Prog Brain Res 114:209-223.

LeDoux J (1994) The amygdala: contributions to fear and stress. Semin Neurosci 6:231-237.

LeDoux J, Cicchetti P, Xagoraris A, Romanski L (1990) The amygdaloid nucleus: sensory interface of the amygdala in fear conditioning. J Neurosci 10:1062-1069.

Li X, Armony J, LeDoux J (1996) GABA $_{A}$ and GABA $_{B}$ receptors differentially regulate synaptic transmission in the auditory pathway: an in vivo microiontophoretic study and model. Synapse 24:115-124.

Liang KC (1998) Posttraining intra-amygdala infusion of 5-HT1A agonists or antagonists affected memory in an inhibitory avoidance task. Soc Neurosci Abstr 12:844.8.

McDonald AJ (1985) Immunohistochemical identification of GABAcontaining neurons in the rat basolateral amygdala. Neurosci Lett 53:203-207.

Moore R, Halaris A (1975) Hippocampal innervation by serotonin neurons of the midbrain raphe in the rat. J Comp Neurol 164:171-183.

Morales M, Bloom F (1997) The 5-HT3 receptor is present in different subpopulations of GABAergic neurons in the rat telencephalon. J Neurosci 17:3157-3167.

Paxinos G, Watson C (1986) The rat brain in stereotaxic coordinates, Ed 2. New York: Academic.

Pitkanen A, Savander V, LeDoux J (1997) Organization of intraamygdaloid circuits in the rat: an emerging framework for understanding functions of the amygdala. Trends Neurosci 20:517-523.

Radja F, Laporte A, Daval G, Verge D, Gozlan H, Hamon M (1991) Autoradiography of serotonin receptor subtypes in the central nervous system. Neurochem Int 18:1-15.

Romanski L, LeDoux J (1993) Information cascade from primary auditory cortex to the amygdala: corticortical and corticoamygdaloid projections of temporal cortex in the rat. Cereb Cortex 3:515-532.

Ropert N, Guy N (1991) Serotonin facilitates GABAergic transmission in the CA1 region of the rat hippocampus in vitro. J Physiol 441:121-136.

Sadikot AF, Parent A (1990) The monoaminergic innervation of the amygdala in the squirrel monkey: an immunohistochemical study. Neuroscience 36:431-447.

Sheldon P, Aghajanian G (1990) Serotonin (5-HT) induces IPSPs in pyramidal layer cells of rat piriform cortex: evidence for the involvement of a 5-HT2-activated interneuron. Brain Res 506:62-69.

Stutzmann G, McEwen B, LeDoux, J (1998) Serotonin modulation of sensory inputs to the lateral amygdala: dependency on corticosterone. J Neurosci 18:9529-9538. 